Journal of Social Sciences 5(3): 206-211, 2009

ISSN 1549-3652

(C) 2009 Science Publications

\title{
Boarding School Students Monitoring Systems (E-ID) Using Radio Frequency Identification
}

\author{
Herdawatie Bt Abdul Kadir, Mohd Helmy Abd. Wahab and Siti Nurul Aqmariah Bt Mohd Kanafiah \\ Faculty of Electrical and Electronic Engineering, \\ University Tun Hussein Onn Malaysia, 86400 Parit Raja, Batu Pahat, Johor, Malaysia
}

\begin{abstract}
Problem statement: Monitoring Boarding school student movement using the oldfashioned study system is inefficient and brings difficulty to the hostel management to check attendance manually. By using RFID technology, student movement is quick and easy. Approach: The application of RFID Matrix Card system as a boarding school students monitoring system (EID) were purposed to improve school management system and to monitor interest group movement. The RFID tags enable school management to track the students movements in and out of the hostel. An individual without RFID card will trigger the alarm and this will inform school management about availability of students using an online monitoring system. Results: This system used main component of passive RFID system, database management system and wireless networking. When RFID tag pass through the RFID reader in read range zone, system recorded data from the RFID tag to the database system. Data sent online to the management for the supervision of students. This ease management to monitor availability of boarding school students and access the students personal records. Conclusion: This research study offer important implication for monitoring the boarding school students. Although this project cannot control the punctuation of student but it can ease the workload of school management and save time.
\end{abstract}

Key words: RFID, monitoring system, passive tag, boarding school

\section{INTRODUCTION}

Auto-ID technologies have been used to reduce the time and man power to input data manually. There are still some auto-ID technologies require someone to manually scan the tag to capture the data such as in barcoding technology. In contrast, Radio Technology Identification (RFID) is a technology which does not require anyone to do any manual scanning, but it uses radio waves to detect man, animals, data, or any other materials plugged with RFID tag automatically. The RFID tag combines a type of microchip and an antenna, to detect the subjects and transmit the data. The subjects are detected by the microchip and the information is transmitted by an antenna. The advantage that RFID can detect subjects from a range makes it highly usable for data storage or data extraction.

An RFID system is composed of three main components; (1) An antenna or coil, (2) A transceiver (with decoder) and (3) An RFID tag. The antenna will transmit radio signal to activate the tag so the data could be read or written. Data storage and retrieval purposes are performed using a special device, the RFID tag. The tag is very small and can be placed anywhere on anything or inserted in human body.

Literatures show that RFID has been applied in various fields such as supply chain ${ }^{[1]}$, construction ${ }^{[2]}$ and library ${ }^{[3]}$ and health ${ }^{[4]}$, the use of RFID system can reduce operating cost and simplify data storage and retrieval. In the medical or health line, RFID is used to store patient records and preparation of medicine.

Based on the above-described overview on RFID, this study attempts to apply the technology in monitoring students of Boarding Schools (BS). Currently, the BS management has to record students in and out of the school manually. From an initial study involving three BS in Malaysia, the management found that maintaining students in/out records are difficult. In current system, misinformation always happens because students tend to provide untrue information. This results in difficulties to locate students if necessary.

This study proposes a system named Boarding School Students Monitoring Systems (E-ID) to solve the above-described limitation, with the aims to outline

Corresponding Author: Herdawatie Bt Abdul Kadir, Faculty of Electrical and Electronic Engineering, Universitiy Tun Hussein Onn Malaysia, 86400 Parit Raja, Batu Pahat, Johor, Malaysia 
the system requirement, to investigate the effects of environment to RFID signal and to justify whether RFID can be used for monitoring students in/out of BS.

\section{MATERIALS AND METHODS}

RFID is getting attention in many areas of application toward increasing the ability to obtain a vast array of data of chosen entity that can be physically tagged and wirelessly scanned ${ }^{[5]}$.

In construction industry, RFID system is used to obtain information about the truck and its contents ${ }^{[6]}$. The device allows the trucks to be scanned while in motion as they pass through a gate, material to be scan while being picked up by material-handling equipment and misplaced items to be found by scanning in likely places. Besides that, it can be scanned several items simultaneously such as a truckload of material or several concrete cylinders in a tank and ability for the tag to retain information on the contents of trucks or attributes of the construction material. To detect hazardous workplaces and worker safety, RFID are used in surface and underground work environments such as mining operations ${ }^{[7]}$. These new developments in show promise for reducing the number of collisions that cause injury to many workers.

Also, RFID technology has a growing market in home and business security systems. RFID cards may be used to provide a hands-free access control system. With an embedded tag that acts as the 'key' to apartments and homes, the card opens the door when it passes within close proximity, eliminating the need to tumble with keys or locks ${ }^{[8,9]}$. Agricultural fields may well be considered the birthplace of RFID technologies is to manage animals. RFID animal tag is embedded under the animal's skin; most commonly known use is to identify household pets. RFID tags help farmer to identify and track their farm animals, also used in wildlife conservation ${ }^{[10]}$.

And more recently, near microscopic TIRIS (Texas Instruments Registration and Identification System) tags are being implanted in Antarctic Penguins for longterm study ${ }^{[11]}$. In libraries system, RFID can be highly beneficial, particularly for circulation staff. The implementation of RFID promises fast patron self check, decrease pilferage and offer accurate and timely inventory management ${ }^{[12]}$.

Health monitoring in hospital has been an interest to researchers and healthcare practitioners for a long time The RFID technology help to track processes in patient and medical equipment also been discussed in ${ }^{[13,14]}$. Although tagging object, such as medical equipment, drugs, etc, is a potential area for RFID in hospitals, the tagging of patients involves both more value \& more challenging because it involves patients, physicians and medical know-how and practical \& organization issues. Based on the success stories in the above paragraphs, this study deduces that RFID can be implemented in monitoring BS students. In overall concept, RFID will be detected when someone with an RFID tag passes through the RFID reader. Then, data from RFID tag will be searched in the database. List of students in the database will be displayed on the host computer and is directly sent to the school management using online system. Figure 1 shows an illustration on the interaction flows in BS monitoring system.

The system requirement is divided into hardware and software part. First, the project criteria was examined and outlined in the following paragraph. The remaining paragraphs elaborate the hardware and software. The criteria for E-ID were first determined, through observations during the initial interview with the three BS. Accordingly, some important criteria for consideration are listed with brief proposed solution in Table 1. Figure 2 shows the overall design and implementation of E-ID. Briefly, E-ID comprised of three parts, the system interface, the processing engines and the database. These three parts are connected through the Open Database Connectivity Driver (ODBC). In addition, E-ID employs a database with three table; (1) Attendance, (2) Student_Registration and (3) Users. Table 2 provides descriptions about each table.

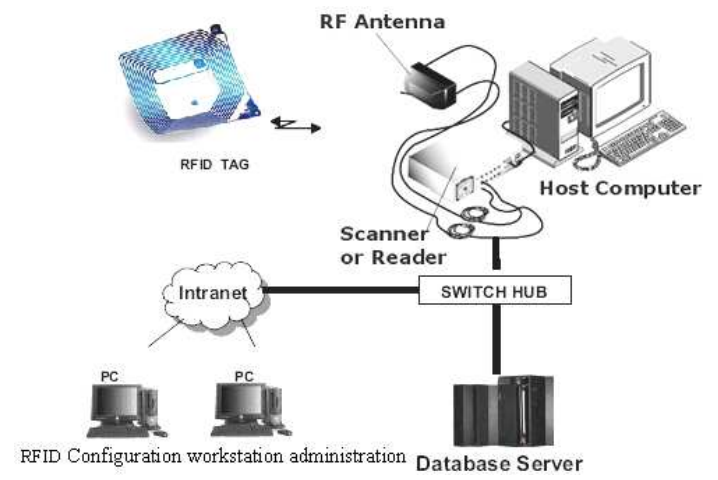

Fig. 1: System architecture of monitoring system

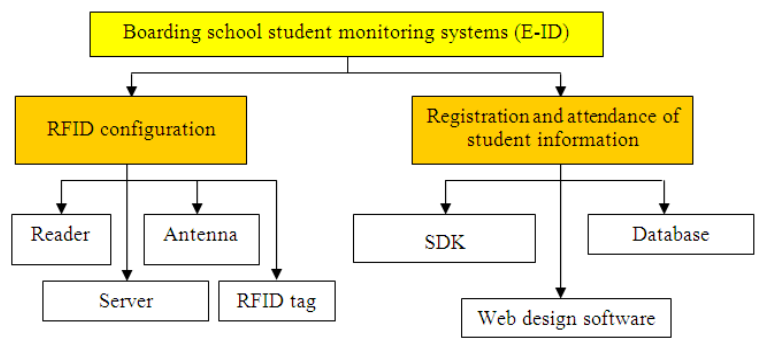

Fig. 2: Development of hardware and software system 
Table 1: E-ID system specification

\begin{tabular}{|c|c|}
\hline Criteria & Proposed solution \\
\hline Type of RFID & Passive \\
\hline Frequency & $13.56 \mathrm{MHz}$ (high frequency) \\
\hline Range & 3 meters \\
\hline Life & Unlimited \\
\hline \multirow[t]{4}{*}{$\begin{array}{l}\text { Source of power } \\
\text { supply }\end{array}$} & $\begin{array}{l}\text { Uses the radio wave broadcast } \\
\text { by the reader to energize its }\end{array}$ \\
\hline & $\begin{array}{l}\text { operation (magnetic alternating field) } \\
\text { Principle is similar to an electromagnet }\end{array}$ \\
\hline & $\begin{array}{l}\text { transferring power via magnetic force, } \\
\text { but RFID reverse the process to }\end{array}$ \\
\hline & $\begin{array}{l}\text { transform magnetic force into } \\
\text { a power source. }\end{array}$ \\
\hline Other typical application & $\begin{array}{l}\text { Access control, item level } \\
\text { tracking, smart card }\end{array}$ \\
\hline Networking & Local area network \\
\hline
\end{tabular}

Table 2: Tables in E-ID with attributes

\begin{tabular}{llll}
\hline Table & Function & Field name & Data type \\
\hline Attendance & save the & No (primary key) & Auto No. \\
& attendance & Matric No. & Text \\
& & Tag ID & Text \\
& Name & Text \\
& & Time & Date/Time \\
& & Date & Date/time \\
Student_Registration & Save the & Status & Text \\
& student & (Primary) key & Text \\
& information & \\
& & Tag ID & Text \\
& Student name & Text \\
& Registration_Date_Time & Date/Time \\
& IC_No. & Text \\
& Sesi_form & Text \\
& Address & Text \\
& Postcode & Text \\
& City & Text \\
& State & Text \\
& Gender & Text \\
& Phone_No & Text \\
& Handphone_No. & Text \\
& Email & Text \\
& Block & Text \\
& & Pics & Text \\
& & Save the user ID & Text \\
& and Password & \\
\hline & &
\end{tabular}

The implementation of E-ID is elaborated in this paragraph and the remaining. First, the RFID set should be turn $\mathrm{ON}$ and the tag must be placed in a reading range. Antenna will generated the radio frequency field to the tag. Then, RFID will be detected after the reader receive signal from the tag. There are two inspections, either the RFID tag has been registered or RFID tag has not been registered. E-ID provides an option to register the tag which has not yet been registered in which the flow is illustrated in Fig. 3. Meanwhile, Fig. 4 shows the interaction flow if the tag has been registered.

The functions above are combined in E-ID and the model for combined functions is illustrated in Fig. 5. The model above has been experimented, to investigate whether it functions well as intended in different environment.

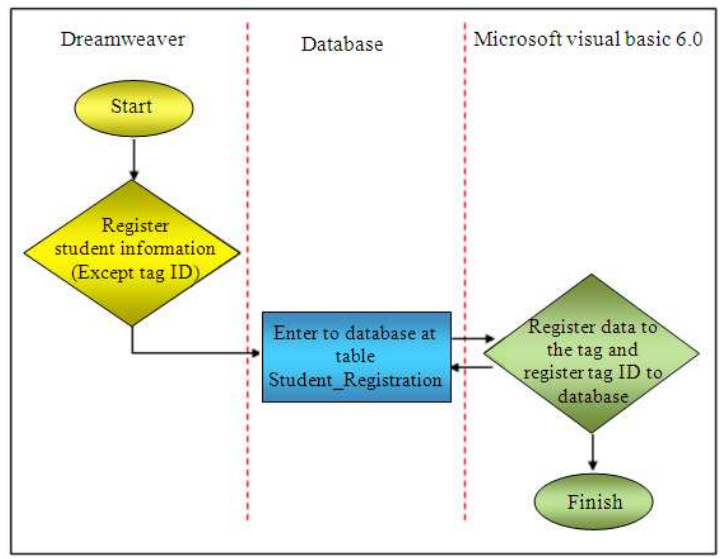

Fig. 3: Registering a new RFID tag

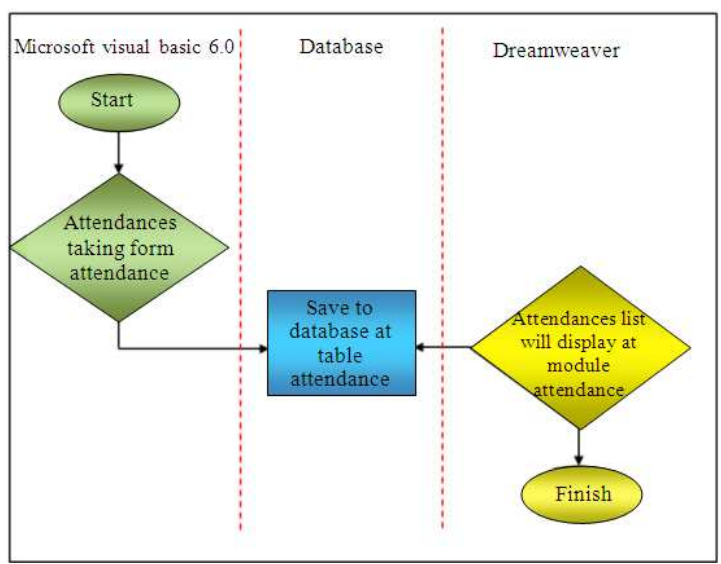

Fig. 4: Attendance taking

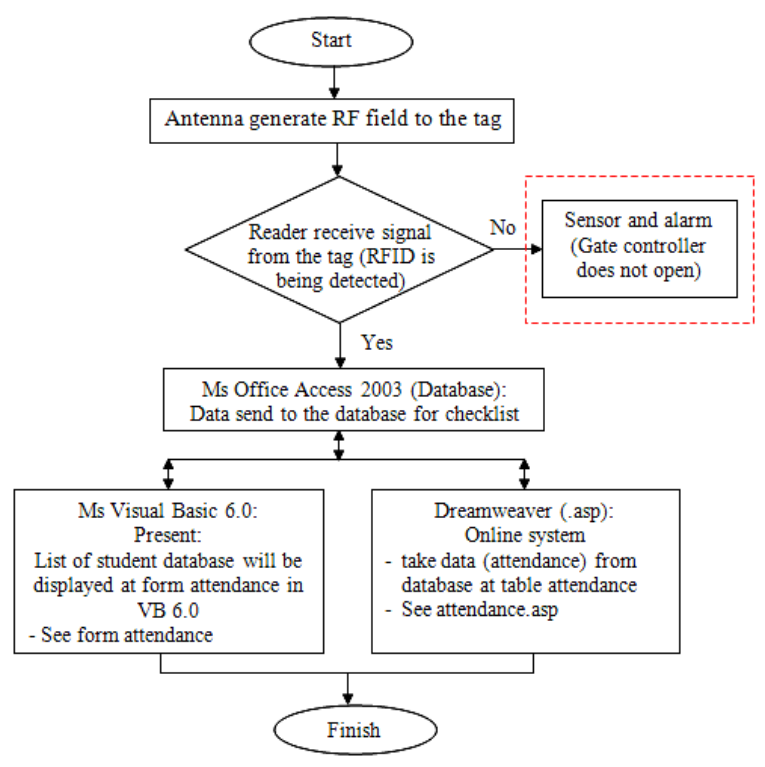

Fig. 5: The E-ID Monitoring system 


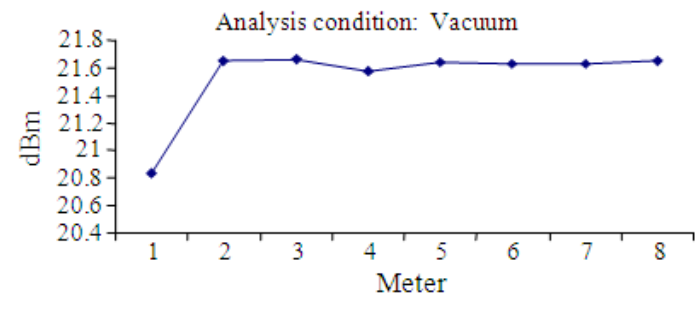

Fig. 6: The effect of the distance v/s conversion of power in vacuum condition

\section{RESULTS}

Due to the nature of geographical area and physical size of the magnetic field produced by the tags, the placing tags in certain geographical areas such as polar region, moisture content and deserts due to any EM discharge may affect E-ID system functionality. Several experiments have been conducted in order to test the functionality and performance of E-ID in different condition which are in shielding room, outside room and outside room with noises present.

In the first condition, the tag and the reader were placed in a noise-free environment. Since a bistatic antenna was used for reading tags, the tags were aligned with respect to the transmit antenna. From the results in Fig. 6, it can be noticed that the operating maximum power in $\mathrm{dBm}$ is $21.65 \mathrm{dBm}$. It conveys meaning that tags give good performance when they are aligned with the transmit antenna and not affected by environment interferences but effected by reflection and absorption; where the signal wave collides with a reflected wave and hits a solid object, the object may absorb some of the waves energy.

In this second condition, the tag and reader antenna were placed outside the room without any noise in terms of people and hand phone. Since a bistatic antenna was used for reading tags, the tags were aligned with respect to the transmit antenna. From the results in Fig. 7, it can be noticed that the operating maximum power is $24.14 \mathrm{dBm}$, due to minimum environments producing the electromagnetic (EM) noise and normal moisture levels within the air.

The radiation pattern of an RFID tag antenna determines the ability to read the tag in any orientation but it still has a problem with the RFID tag that cannot read the data. When RFID tags are exposed to noise such as of people and hand phone, the operation maximum power is $13.724 \mathrm{dBm}$, which can be seen in the results in Fig. 8. A bistatic antenna was used for reading tags, the tags were aligned with respect to the transmit antenna. There disturbance occur in data analysis because of the present of many noises in the environment due to carrier interference; absorption, reflecting /nulling, electrical and skip interference.

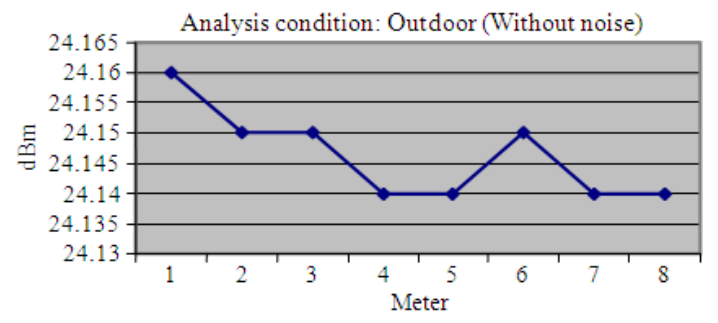

Fig. 7: The effect of the distance v/s conversion of power in outdoor without noise and normal moisture level

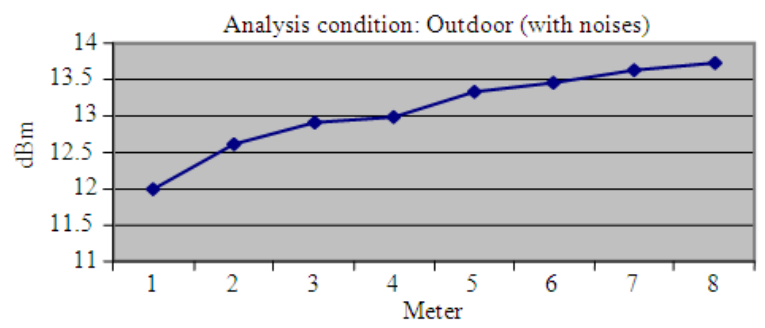

Fig. 8: The effect of the distance v/s conversion of power, outdoor with noise and normal moisture level

\section{DISCUSSION}

From the results, although these tags are slightly influenced by different conditions to provide power to the tag and have different reading ranges, but there is nothing about them which makes them safe against a variant of this power-analysis attack due to environment changes especially by hand phones. The modern hand phones air interface protocol is more complex than the RFID air interface, it can be used to attack and kill UHF tags although have different frequencies and antennas. With capable of attacking HF tags and this situation is very crucial while the E-ID system is acquiring data from the matrix card due to the data lost and conflict.

Figure 9 shows the Flow Chart for Boarding School Student. Monitoring System in this project. First, the RFID set should be turn on and the tag must be placed in a reading range. Antenna will generated the radio frequency field to the tag. Then, RFID will be detected after reader receive signal from the tag. If RFID tag has been registered, system will take the attendance automatically and the label at the interface will show the message 'Please enter'. Attendance student will be saved in database. If tag has not been registered, the label in the interface will show the message 'No data available, please register '. Some snapshots of E-ID are provided in Fig. 10 and 11. 


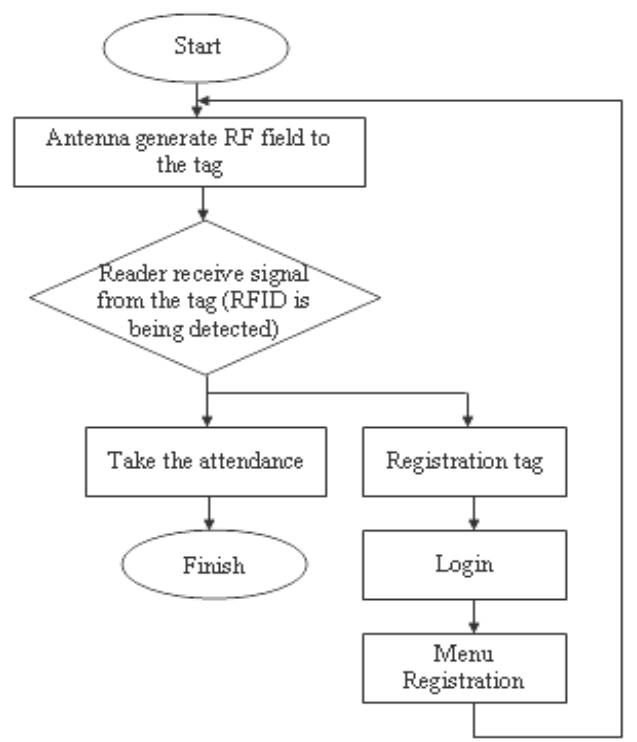

Fig. 9: Boarding school student monitoring system (Visual Basic System)

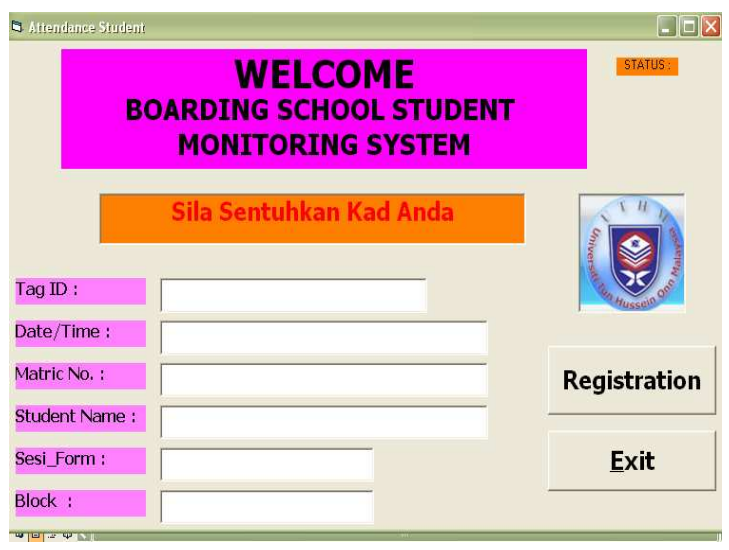

Fig. 10: Main menu for monitoring system

The web server (dream-weaver) has been developed to ease the management system to monitor the student movement in everywhere. The function of web server is to register the student information (except Tag ID) and to look the attendance list of the students in everywhere in the web server without looking at the static place using the old-fashioned paper system. To display to the web server, it must be saved at C: /Inetpub/wwwroot/UTHM after install the Internet Information Service (IIS). This system has chosen ASP (Active Server Page) as a programming language for the Web Server. Figure 12 shows the Flow Chart of the linked pages Development System. A snapshot of E-ID online system is provided in Fig. 13.

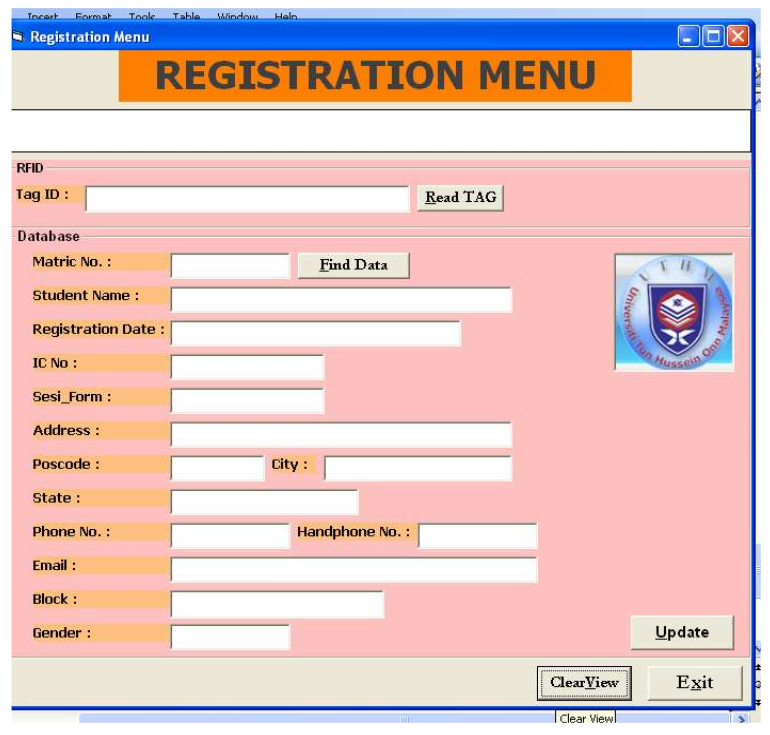

Fig. 11: Registration menu

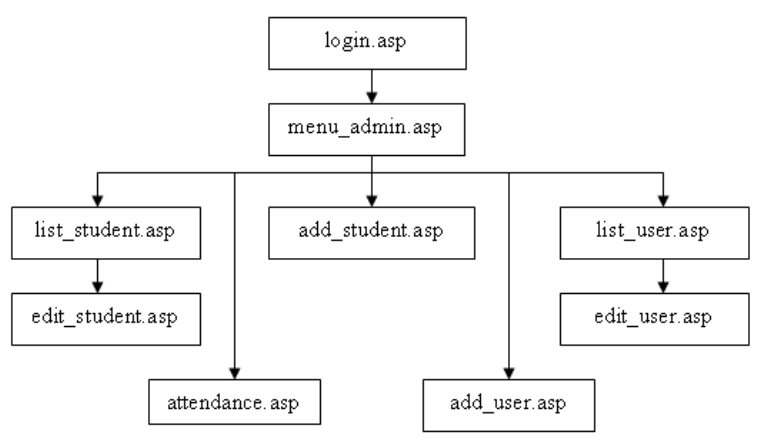

Fig. 12: The organization of Web administration

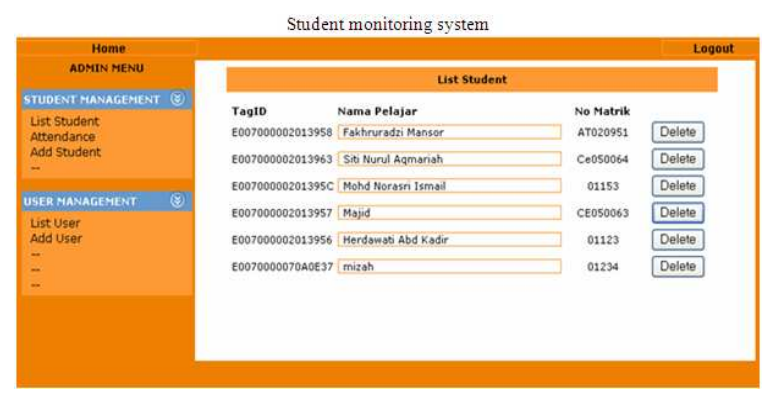

Fig. 13: Student management menu

\section{CONCLUSION}

The earlier part of this article reveals the requirement to develop E-ID, which was proposed to monitor students' movement in BS. Next, E-ID was experimented in three different conditions, to 
investigate whether RFID is influenced by noise. It was found that tags give better performance when they are aligned with the transmit antenna, the radiation pattern of an RFID tag antenna determines the ability to read the tag in any orientation and RFID performance is low when it operates in the presence of an interfering signal.

To this point, this study has fulfilled the first two aims. In short conclusion, based on the above two findings, this study deduces that RFID is suitable to be implemented for monitoring students of BS. As for future research expansion, some system defensive mechanism will be added to enable the system to be immune outside knock such as manipulation, sniffing of radio signal for replicate/ modify signals and viruses.

\section{ACKNOWLEDGEMENT}

This study was supported in part by Centre of Research and Innovation Management UTHM under Short Term Grant.

\section{REFERENCES}

1. Ozelkan, E.C., Y. Sireli, M.P. Muñoz and S. Mahadevan, 2006. A decision model to analyze costs and benefits of RFID for superior supply chain performance. Proceeding of the Technology Management for the Global Future, July 2006, IEEE Xplore Press, Istanbul, pp: 610-617. DOI: 10.1109/PICMET.2006.296660

2. Lu, M., W. Chen, X. Shen, H.C. Lam and J. Liu, 2007. Positioning and tracking construction vehicles in highly dense urban areas and building construction sites. Automat. Construct., 16: 47-656. DOI: 10.1016/j.autcon.2006.11.001

3. Singh, J., N. Brar and C. Fong, 2006. The state of RFID applications in libraries. Inform. Technol. Libraries, 25: 24-32. http://cat.inist.fr/?aModele $=$ afficheN\&cpsidt $=17860855$

4. Wang, S.W., W.H. Chen, C.H. Ong, L. Liu and Y.W. Chuang, 2006. RFID Application in hospitals: A case study on a demonstration rfid project in a Taiwan hospital. Proceeding of the 39th Annual Hawaii International Conference on System Sciences, Jan. 04-07, IEEE Xplore Press, USA., pp: 184-184. DOI: 10.1109/HICSS.2006.422

5. Curtin, J., R.J. Kauffman and F.J. Riggins, 2007. Making the 'MOST' out of RFID technology: A research agenda for the study of the adoption, usage and impact of RFID. Inform. Technol. Manage., 8: 87-110. DOI: 10.1007/s10799-0070010-1
6. Jaselskis, E.J., M.R. Anderson, C.T. Jahren and Y. Rodriguez, 1995. Radio frequency identification application construction industry. J. Construct. Eng. $\quad$ Manage., 121: 189-196. http://cat.inist.fr/?aModele $=$ afficheN\&cpsidt $=3535596$

7. Ruff, T.M. and D. Hession-Kunz, 2001. Application of radio-frequency identification systems to collision avoidance in metal/nonmetal mines. IEEE Trans. Ind. Appli., 37: 112-116. DOI: 10.1109/28.903133

8. Pala, Z. and N. Inanc, 2007. Smart parking applications using RFID technology RFID. Proceeding of the 1st Annual Eurasia, Sept. 5-6, IEEE Xplore Press, Istanbul, pp: 1-3. DOI: 10.1109/RFIDEURASIA.2007.4368108.

9. Fujikawa, M., H. Doi and S. Tsujii, 2006. Proposal for a new home security system in terms of userfriendliness and prompt intrusion notification. Proceeding of the IEEE International Conference on Computational Intelligence for Homeland Security and Personal Safety, Oct. 16-17, IEEE Xplore Press, Alexandria, VA., pp: 61-66. DOI: 10.1109/CIHSPS.2006.313308

10. Laursen, W., 2006. Managing the mega flock (individual animal management systems). IEEE Rev., 52: 38-42.

http://ieeexplore.ieee.org/stamp/stamp.jsp?tp=\&arn umber $=1599355 \&$ isnumber $=33628$

11. Beigel, M., 1997. The penguin project: RFID technology development.

12. Paul, G. and T. Vanesa, 2007. Work in progress: Performance and reliability of Radio Frequency Identification (RFID) library system. Proceeding of the International Conference on Multimedia and Ubiquitous Engineering, Apr. 26-28, IEEE Xplore Press, USA., pp: 1143-1146. DOI: 10.1109/MUE.2007.219

13. Sangwan, R.S., R.G. Qiu and D. Jessen, 2005. Using RFID tags for tracking patients, charts and medical equipment within an integrated health delivery network. Proceeding of the IEEE Networking, Sensing and Control, Mar. 19-22, IEEE Xplore Press, USA., pp: 1070-1074. DOI: 10.1109/ICNSC.2005.1461346

14. Cavalleri, M., R. Morstabilini and G. Reni, 2004. A wearable device for a fully automated in-hospital staff and patient identification. Proceeding of the 26th Annual International Conference on Engineering in Medicine and Biology Society, Sept. 1-5, IEEE Xplore Press, USA., pp: 3278-3281. http://ieeexplore.ieee.org/xpl/freeabs_all.jsp?tp=\&a rnumber $=1403922 \&$ isnumber $=30463$ 